\title{
Article
}

\section{Boron-doped multi-walled carbon nanotubes as sensing material for analysis of dopamine and epinephrine in presence of uric acid}

Tsierkezos, Nikos G., Ritter, Uwe, Thaha, Yudi Nugraha, Knauer, Andrea, Fernandes, Diogo Andre jardoso, Kelarakis, Antonios and McCarthy, Eoin K.

Available at http://clok.uclan.ac.uk/36035/

Tsierkezos, Nikos G., Ritter, Uwe, Thaha, Yudi Nugraha, Knauer, Andrea,

Fernandes, Diogo Andre jardoso, Kelarakis, Antonios ORCID: 0000-0002-8112-

5176 and McCarthy, Eoin K. (2018) Boron-doped multi-walled carbon nanotubes as sensing material for analysis of dopamine and epinephrine in presence of uric acid. Chemical Physics Letters, 710 . pp. 157-167. ISSN 00092614

It is advisable to refer to the publisher's version if you intend to cite from the work. http://dx.doi.org/10.1016/j.cplett.2018.09.007

For more information about UCLan's research in this area go to http://www.uclan.ac.uk/researchgroups/ and search for <name of research Group>.

For information about Research generally at UCLan please go to http://www.uclan.ac.uk/research/

All outputs in CLoK are protected by Intellectual Property Rights law, including Copyright law. Copyright, IPR and Moral Rights for the works on this site are retained by the individual authors and/or other copyright owners. Terms and conditions for use of this material are defined in the policies page. 


\title{
Boron-doped multi-walled carbon nanotubes as sensing material for analysis of dopamine and epinephrine in presence of uric acid
}

\author{
Nikos G. Tsierkezos, ${ }^{1 *}$ Uwe Ritter, ${ }^{1}$ Yudi Nugraha Thaha,,${ }^{1}$ Andrea Knauer, ${ }^{2}$ Diogo Fernandes, ${ }^{3}$ \\ Antonios Kelarakis, ${ }^{3}$ and Eoin K. McCarthy ${ }^{4}$
}

${ }^{1}$ Department of Chemistry, Institute of Chemistry and Biotechnology, Ilmenau University of Technology, Weimarer Straße 25, 98693 Ilmenau, Germany

${ }^{2}$ Department of Physical Chemistry and Micro Reaction Technology, Institute of Chemistry and Biotechnology, Ilmenau University of Technology, Ilmenau, Germany

${ }^{3}$ Centre for Materials Science, School of Physical Sciences and Computing, University of Central Lancashire, Preston, Lancashire PR1 2HE, UK

${ }^{4}$ Advanced Microscopy Laboratory, CRANN, Trinity College Dublin, Dublin 2, Ireland

\section{A B S T R A C T}

Boron-doped multi-walled carbon nanotubes (B-MWCNTs) were synthesized, treated with hydrochloric acid, "piranha" solution, and decorated with gold nanoparticles (AuNPs). BMWCNTs were characterized using Raman spectroscopy, scanning electron- and transmission electron microscopy, and electrochemical techniques. The results exhibit enhanced response and sensitivity of B-MWCNTs upon modification with AuNPs. Analysis of dopamine (DA) and epinephrine (EP) in presence of uric acid (UA) was investigated on B-MWCNTs/AuNPs in pig blood serum. Limits of detection of 0.20 and $0.30 \mu \mathrm{M}$ were estimated for DA and EP, respectively. The findings demonstrate that B-MWCNTs/AuNPs is proper for analysis of DA and EP under coexistence of UA.

Keywords Blood serum - Boron-doped multi-walled carbon nanotubes • Dopamine • Electrochemical sensing $\bullet$ Epinephrine $\bullet$ Gold nanoparticles

Electronic supplementary material: The online version of article contains supplementary material, which is available to authorized users.

\footnotetext{
* Corresponding author at: Department of Chemistry, Institute of Chemistry and Biotechnology, Ilmenau University of Technology, Weimarer Straße 25, 98693 Ilmenau, Germany. Tel: +49 367769 3647. E-mail address: nikos.tsierkezos@tu-ilmenau.de (Nikos G. Tsierkezos)
} 


\section{Introduction}

The development of new techniques for fabrication of multi-walled carbon nanotubes that incorporate into their structure boron (further denoted as B-MWCNTs) are of great interest, both academically and commercially. It is, therefore, not surprising that many scientists have fabricated B-MWCNTs with decomposition of numerous boron source materials using various methods, such as catalytic pyrolysis [1,2], electric arc discharge [3], diffusion/solid state reaction [4,5], substitution reaction/solid state reaction [6,7], spark plasma sintering [8], and laser vaporization [9]. However, among these techniques the chemical vapor deposition (CVD) was found to be the most promising and efficient method since it facilitates the production of high yield of B-MWCNTs without by-products.

It was already recognised that the doping of MWCNTs with boron can induce significant tubule morphology changes in nanotubes, as for instance, it leads to an enhancement of their graphitization [10-12]. In addition, the doping of carbon nanotubes with boron leads to lowering of Fermi level into the valence band [13,14]. Furthermore, the boron-doping improves the field emission properties by increasing the binding energies of carboxyl groups in carbon nanotubes $[15,16]$. It is, thus, not surprising that B-MWCNTs are better transparent conductors compared to undoped pristine MWCNTs, and consequently, they can be used as superconductor materials in various electrochemical applications [17].

Dopamine (DA) and epinephrine (EP) are essential catecholamine neurotransmitters that play an important role in transmission of nerve impulse and are associated with large variety of physiological processes and illnesses. Monitoring DA and EP in human blood plasma and urine gains great attention since variations in their concentrations lead to illnesses such as Parkinson's disease, Huntington's disease, and schizophrenia [18-20]. Classical approaches to detect DA and EP are electrochemical methods, such as amperometry, cyclic voltammetry, and differential pulse voltammetry. These techniques provide quantitative information about neurotransmitter concentrations around cells, in brain slices, as well as in vivo [21,22]. Furthermore, the electrochemical techniques are preferred due to their relatively low cost, high selectivity and sensitivity, less time consuming, and simple instrumentation. However, in biological fluids DA and EP frequently coexist with uric acid (UA) that is present at higher concentrations and is oxidized at potential very close to that of DA and EP. Consequently, the electrochemical analysis of DA and EP in presence of UA on conventional electrodes, such as platinum, gold, and glassy carbon, usually suffers by interferences due to overlapping of oxidation waves of interfering analytes. Thus, it still remains real great challenge to develop 
simple, inexpensive, rapid, selective, and sensitive sensors for simultaneous electrochemical detection of DA and EP in the presence of UA in biological fluids.

In the present work we report on fabrication of novel composite films consisting of BMWCNTs by means of CVD technique. Specifically, B-MWCNTs were fabricated onto silicon/silicon oxide substrate with thermal decomposition of triethyl borate (boron- and carbon source material, TEB) and ethanol (carbon source material, EtOH) in presence of ferrocene (catalyst, $\mathrm{FeCp}_{2}$ ). In order to study the effect of acid and oxidative treatment on electrochemical properties of carbon nanotubes, the synthesized B-MWCNTs were treated with hydrochloric acid (B-MWCNTs/HCl) and "piranha" solution (mixture of sulfuric acid and hydrogen peroxide) (B-MWCNTs/Piranha), respectively. Furthermore, modification of B-MWCNTs with gold nanoparticles (B-MWCNTs/AuNPs) was also carried out. The untreated, acid and oxidative treated and AuNPs-modified B-MWCNTs were characterized by means of Raman spectroscopy, scanning electron microscopy (SEM), and transmission electron microscopy (TEM). In addition, the electrochemical responses of untreated, treated, and modified BMWCNTs towards ferrocyanide/ferricyanide, $\left[\mathrm{Fe}(\mathrm{CN})_{6}\right]^{3-/ 4-}$ in potassium chloride solution were probed. An enhanced improvement of electrochemical response and sensitivity of BMWCNTs upon their modification with AuNPs was observed. The B-MWCNTs/AuNPs composite film was successfully applied for electrochemical analysis of dopamine (DA) and epinephrine (EP) either individually or in presence of an excess of uric acid (UA) in phosphate puffer solution (pH 7.4) as well as in pig blood serum.

\section{Experimental details}

\subsection{Chemicals and solutions}

Triethyl borate (Boric acid triethyl ester) (>99.0\%), ethyl alcohol (>99.5\%), ferrocene (>98.0\%), potassium hexacyanoferrate(III) (>99.0\%), potassium hexacyanoferrate(II) trihydrate $(>98.5 \%)$, dopamine $(>99.0 \%)$, epinephrine $(>99.0 \%)$, uric acid $(>98.0 \%)$, and potassium chloride $(>99.0 \%)$ were purchased from Sigma-Aldrich and were used as received without any further purification. Pig blood serum was purchased from Bio \& SELL GmbH. The blood serum samples were stored in polypropylene tubes at $-20{ }^{\circ} \mathrm{C}$ until analysis.

A stock solution of $\mathrm{K}_{3}\left[\mathrm{Fe}(\mathrm{CN})_{6}\right] / \mathrm{K}_{4}\left[\mathrm{Fe}(\mathrm{CN})_{6}\right]\left(1.0 \times 10^{-2} \mathrm{M}\right)$ was prepared by dissolving the appropriate amounts of salts in $\mathrm{KCl}(1.0 \mathrm{M})$ aqueous solution. For the preparation of solutions doubly distilled water was used. The solutions of $\left[\mathrm{Fe}(\mathrm{CN})_{6}\right]^{3-14-}$ redox system with various concentrations were prepared directly in electrochemical cell with progressive addition of appropriate volume of the stock solution in $1.0 \mathrm{M} \mathrm{KCl}$ aqueous solution. 
Solutions of DA, EP, and UA of desired concentration were prepared immediately prior the electrochemistry measurements directly in electrochemical cell with addition of proper volumes of stock solution of each analyte $\left(1.0 \times 10^{-2} \mathrm{M}\right)$ into phosphate puffer solution (PBS, $\mathrm{pH}$ 7.4). The electrochemistry measurements were performed at $\mathrm{pH} 7.4$ since this $\mathrm{pH}$ value is very close to the physiological $\mathrm{pH}$ value of 7.365 . Measurements in pig blood serum were additionally carried out. The blood serum samples were diluted with the PBS ( $\mathrm{pH}$ 7.4) before analysis without further pre-treatment. A quantitative analysis was carried out by adding proper volumes of stock solutions of analytes into diluted blood serum samples.

\subsection{Fabrication of B-MWCNTs composite films}

B-MWCNTs were grown directly onto silicon/silicon oxide substrate by means of CVD with decomposition of $1.0 \%$ w/w TEB (carbon- and boron source material) and EtOH (carbon source material) in the presence of $1.0 \% \mathrm{w} / \mathrm{w} \mathrm{FeCp} 2$ (catalyst). For the growth process, the $\mathrm{TEB} / \mathrm{EtOH} / \mathrm{FeCp}_{2}$ ternary mixture was sprayed into the furnace at the temperature of $850{ }^{\circ} \mathrm{C}$ through a syringe with flow rate of $10 \mathrm{~mL} \mathrm{~h}^{-1}$ (the growing time was fixed at about $30 \mathrm{~min}$ ). In all cases, the pyrolysis experiments were carried out by spraying a volume of about $5 \mathrm{~mL}$ of $\mathrm{TEB} / \mathrm{EtOH} / \mathrm{FeCp}_{2}$ ternary mixture. The scheme of CVD apparatus and experimental details concerning the pyrolysis process were already reported in previous published articles [23,24].

The electrical contacting of working electrode for electrochemistry measurements was achieved as follows: the B-MWCNTs-based composite films were initially connected to platinum wire by using silver conducting coating, and once the silver coating was dried, the silver conducting part of composite films was fully covered with varnish protective coating (Fig.S1; ESM) [25].

\subsection{Synthesis of AuNPs and preparation of B-MWCNTs/AuNPs composite films}

The gold nanoparticles were prepared according the well-known Turkevich method [26] by heating a mixture of $500 \mu 1 \mathrm{HAuCl}_{4}\left(5.0 \times 10^{-4} \mathrm{M}\right)$ and $500 \mu 1$ sodium citrate $\left(1.7 \times 10^{-3} \mathrm{M}\right)$ solutions to boiling for about $20 \mathrm{~min}$ in capped glass bottle. The solution was heated till it had permanent reddish-pink color. The synthesized particles show a characteristic plasmon absorption in UV-Vis spectrophotometry near $520 \mathrm{~nm}$ (Fig.S2; ESM). The average diameter was determined be means of differential centrifugal sedimentation spectroscopy (DCS) and was $11.5 \mathrm{~nm}$ with a peak half width of $1.9 \mathrm{~nm}$ (Fig.S3; ESM).

B-MWCNTs were decorated with synthesized AuNPs according to following procedure: the B-MWCNTs film was initially immersed in aqueous solution of sodium citrate 
$(2.5 \mathrm{mM})$ and left in solution for about $10 \mathrm{~min}$. After this treatment, the film was dried in the air for about $2 \mathrm{~h}$ at the room temperature. Afterwards, the fabricated colloidal solution of AuNPs was dropped onto treated B-MWCNTs film using a micropipette and let for drying under room conditions. Finally, the composite film was carefully washed with distilled water.

\subsection{Apparatus and experiments}

The electrochemistry measurements were carried out on electrochemical working station Zahner (IM6/6EX, Germany). The recorded cyclic voltammograms (CVs) and electrochemical impedance spectra (EIS) were analyzed and simulated, respectively, by means of Thales software (version 4.15). The EIS spectra were recorded in the frequency range of 0.1 $\mathrm{Hz}-100 \mathrm{kHz}$ at the half-wave potential of studied $\left[\mathrm{Fe}(\mathrm{CN})_{6}\right]^{3-14-}$ redox system. Three-electrode system was used for electrochemistry studies. Namely, as working electrode, the fabricated BMWCNTs-based composite films were applied, while as auxiliary and reference electrodes, a platinum plate and $\mathrm{Ag} / \mathrm{AgCl}$ (saturated $\mathrm{KCl}$ ) electrode, respectively, were used. The electrochemistry measurements were performed at the room temperature. Prior electrochemistry measurements, the solutions were deoxygenated by purging with high-purity nitrogen. More details regarding the electrochemistry measurements were already reported in our previous published articles [27,28].

The Raman spectra of untreated, acid and oxidative treated and AuNPs-modified BMWCNTs were recorded using a microscope-fitted Horiba Jobin Yvon HR800 Raman spectrometer that was calibrated using a Si substrate. The Raman spectra were collected within the range of 1000-2000 $\mathrm{cm}^{-1}$ (scanning intervals of $1.66 \mathrm{~cm}^{-1}$ ) with a slit and hole of 300 and $200 \mathrm{~cm}^{-1}$, respectively. An air cooled CLDS point mode diode $532 \mathrm{~nm}$ laser was used, and the radiation was limited to $10 \%$ in order to avoid damage of the carbon nanotubes samples. The spectra were averaged by 10 accumulations of $2 \mathrm{~s}$ each (using LabSpec 6 software).

The morphology and elemental composition of untreated, acid and oxidative treated and AuNPs-modified B-MWCNTs were examined by transmission electron microscope (FEI Titan S/TEM 80-300 kV) and scanning electron microscope (Zeiss ULTRA Plus SEM) equipped with an energy dispersive $\mathrm{X}$-ray spectrometer.

\section{Results and discussion}

\subsection{Scanning electron and transmission electron microscopic analysis}

The SEM and TEM techniques were used to explore the surface of untreated, acid and oxidative treated, and AuNPs-modified B-MWCNTs as well as to observe directly the morphology and structure of the synthesized carbon nanotubes. Selected SEM and TEM 
micrographs obtained for B-MWCNTs, B-MWCNTs/HCl, B-MWCNTs/Piranha, and BMWCNTs/AuNPs composite films, are shown in Figs.1 and 2, respectively.

The SEM images taken for untreated B-MWCNTs show that the nanotubes are distributed homogenously onto the surface of silicon/silicon oxide substrate and are quite clean and free of amorphous carbon. The low magnification of SEM image shows the heterogeneity of B-MWCNTs structure. Namely, as it can be clearly seen the B-MWCNTs possess asymmetric structure (Y-shaped). The SEM micrographs exhibit the presence of massive (tubby) long carbon nanotubes (rods) that possess sidewalls defects from which additional tiny and thin nanotubes (branches) can be grown (Fig.1a-b). The Y-junction structure is attributed to defects along the axis of nanotubes resulted from reduction of local hexagonal symmetry of nanotubes caused upon their doping with boron [29-31]. Y-junction structure can be appeared with the disruption of hexagonal structure of graphene layer with introduction of pentagon and heptagon [32]. Theoretical studies demonstrated that the substitution of carbon atom with boron perturbates hexagonal network of carbon nanotubes, and thus, local defects are formed due to the formation of pentagon and heptagon in graphene sheet of carbon nanotubes [33]. Since the reactivity of carbon nanotubes is sensitive to nanotube curvature, it is expected that the different diameters of nanotube rods and branches may lead to variation of their electrochemical properties [34]. In Y-junction structure, the electrons can flow through nanotube branches leading to an increase of active surface area and sensitivity compared to linear structure. The tiny nanotubes can be up to roughly $400 \mathrm{~nm}$ in length, while their upper part holds cyclical-like structure with diameter in the range of 10-20 nm.

The SEM images reveal that upon treatment with hydrochloric acid and piranha solution the structure of nanotubes does not change dramatically (Figs.1c-f). However, elimination of upper and inner parts of carbon nanotubes occurs with acid and oxidative treatment. Similarly, the process for modification of B-MWCNTs with AuNPs leads to elimination of upper and inner parts of nanotubes (Figs.1g-h). As it can be seen in SEM micrographs, the AuNPs (that appear in SEM images as white dots) are dispersed homogeneously on surface of B-MWCNTs and no agglomeration of AuNPs takes place.

The TEM micrographs taken for B-MWCNTs reveal that the nanotubes possess either "cylinder-shaped" or "cone-shaped" structure (Figs.2a-b). In addition, the nanotubes possess uniform distribution in length and diameter. Specifically, according to TEM images, the length of nanotubes lies in range from 200 to $400 \mathrm{~nm}$, while their outer diameter is about 30-50 nm. The TEM images taken for B-MWCNTs/HCl and B-MWCNTs/Piranha confirm that upon treatment with hydrochloric acid the upper and inner parts of carbon nanotubes are eliminated, 
and that fairly empty (unfilled) nanotubes are formed (Figs.2c-f). Similar observation can be made upon decoration of B-MWCNTs with AuNPs (Figs.2g-h). In addition, in TEM images can be clearly observed that the AuNPs (which are seen as black dots) possess diameter of ca. $12 \mathrm{~nm}$ and are homogeneously dispersed on surface of carbon nanotubes.

The electron energy loss spectroscopy (EELS) results obtained for untreated BMWCNTs (Fig.S4; ESM) clearly show the presence of boron along with carbon, oxygen, and iron (catalysts residue). Namely, the findings demonstrate that the upper and inner parts of nanotubes are highly boron doped, while the walls of nanotubes consist exclusively of carbon. Boron is detected along with oxygen indicating that the upper and inner parts of nanotubes consist of boron oxide nanoparticles. In acid and oxidative treated carbon nanotubes only carbon can be detected confirming that upon treatment with hydrochloric acid and piranha solution the boron oxide nanoparticles are eliminated (Fig.S5; ESM). It is, however, probable that the carbon nanotubes are boron doped in low degree. Nevertheless, the small amount of boron that is incorporated into structure of carbon nanotubes cannot be easily detected by means of EELS, since trace dopants may be hard to detect. Therefore, it cannot be fully excluded that small degree of boron doping does not occur during the fabrication of B-MWCNTs.

\subsection{Raman spectroscopy analysis}

Raman spectra recorded for untreated, acid and oxidative treated and AuNPs-modified B-MWCNTs are shown in Fig.3. The extracted Raman parameters are reported in Table 1.

The untreated B-MWCNTs displayed the typical D band, attributed to the disordered carbon (or the k-point photons of $\mathrm{A}_{1 \mathrm{~g}}$ symmetry) and the $\mathrm{G}$ band ascribed to the crystalline structure of the carbon in graphene (the $\mathrm{E}_{2 \mathrm{~g}}$ stretching mode of graphene) $[35,36]$. The intensity ratio of these two bands $\left(I_{\mathrm{D}} / I_{\mathrm{G}}\right)$ is the measure of defects in structure of carbon nanotubes. When comparing the different types of as-prepared B-MWCNTs and treated and modified BMWCNTs, the higher ratio $I_{\mathrm{D}} / I_{\mathrm{G}}$ after acid and oxidative treatment, and decoration with AuNPs (B-MWCNTs < B-MWCNTs/HCl $\approx$ B-MWCNTs/Piranha $\approx$ B-MWCNTs/AuNPs), suggest a higher degree of structural defects in treated and decorated nanotubes (Table 1). These defects are known to increase the localized $\mathrm{sp}^{3}$ defects in the $\mathrm{sp}^{2}$ network that can lead to better reactivity of carbon nanotubes.

\subsection{Electrochemical response of $\mathrm{B}-\mathrm{MWCNTs}$ towards $\left[\mathrm{Fe}(\mathrm{CN})_{6}\right]^{3-/ 4-} \operatorname{redox}$ system}

Representative $\mathrm{CVs}$ recorded for $\left[\mathrm{Fe}(\mathrm{CN})_{6}\right]^{3-/ 4-}(1.0 \mathrm{M} \mathrm{KCl})$ on B-MWCNTs, BMWCNTs/HCl, B-MWCNTs/Piranha, and MWCNTs/AuNPs composite films at the scan rate 
of $0.02 \mathrm{~V} \cdot \mathrm{s}^{-1}$ showing the effect of variation of concentration of redox system are presented in Fig.4. The estimated electrochemical parameters for $\left[\mathrm{Fe}(\mathrm{CN})_{6}\right]^{3-/ 4-}$ on various composite films are reported in Table 2.

As it can be seen in recorded CVs, during the anodic and cathodic scans a pair of welldefined reversible oxidation and reduction waves lying at about $E_{\mathrm{p}}{ }^{\mathrm{ox}} \approx 0.35 \mathrm{~V}$ ( $v s$. $\mathrm{Ag} / \mathrm{AgCl}$ ) and $E_{\mathrm{p}}{ }^{\text {red }} \approx 0.20 \mathrm{~V}$ (vs. $\mathrm{Ag} / \mathrm{AgCl}$ ), respectively, appear that correspond to one-electron transfer involving the $\left[\mathrm{Fe}(\mathrm{CN})_{6}\right]^{3-/ 4-}$ redox couple. The half-wave potential of $\left[\mathrm{Fe}(\mathrm{CN})_{6}\right]^{3-14-}$ on untreated, treated, and modified B-MWCNTs, estimated as the average value of oxidation and reduction potentials, lies at about $E_{1 / 2} \approx 0.275 \mathrm{~V}(v s . \mathrm{Ag} / \mathrm{AgCl})$ and is similar within experimental error to that measured for $\left[\mathrm{Fe}(\mathrm{CN})_{6}\right]^{3-/ 4-}$ on pristine, nitrogen-doped and phosphorus-doped multi-walled carbon nanotubes $\left(E_{1 / 2} \approx 0.271 \mathrm{~V} v s . \mathrm{Ag} / \mathrm{AgCl}\right)$ [37].

The oxidation and reduction waves of $\left[\mathrm{Fe}(\mathrm{CN})_{6}\right]^{3-/ 4-}$ on untreated B-MWCNTs appear to slightly more and less positive potential, respectively, compared to those measured on either treated or modified B-MWCNTs. Considering that the anodic and cathodic peak potential separation $\left(\Delta E_{\mathrm{p}}=E_{\mathrm{p}}{ }^{\mathrm{ox}}-E_{\mathrm{p}}{ }^{\text {red }}\right)$ is related to kinetics of electron transfer, this behavior demonstrates slight differences of kinetic for charge transfer for $\left[\mathrm{Fe}(\mathrm{CN})_{6}\right]^{3-14-}$ onto untreated, treated, and modified B-MWCNTs. However, it must be mentioned that the oxidation and reduction of $\left[\mathrm{Fe}(\mathrm{CN})_{6}\right]^{3-/ 4-}$ on studied composite films appear to be strongly dependent on concentration of redox system. Namely, with the increase of concentration of $\left[\mathrm{Fe}(\mathrm{CN})_{6}\right]^{3-/ 4-}$, the oxidation and reduction potentials are shifted slightly to more and less positive potentials, respectively, resulting to an increase of $\Delta E_{\mathrm{p}}$. Since the separation of voltammetric peaks due to electron transfer kinetics is independent of concentration of redox system at a given scan rate, the increase of $\Delta E_{\mathrm{p}}$ with the rise in concentration of redox system can be attributed to uncompensated resistance effect [38]. It is well known that the effect of uncompensated resistance is more evident under conditions resulting in large amplitude currents (for instance high concentrations, large electrode area, and fast scan rates) or involving low dielectric solvents (such as organic solvents). Nevertheless, in spite of slight kinetic differences, the studied redox system $\left[\mathrm{Fe}(\mathrm{CN})_{6}\right]^{3-/ 4-}$ appears to be reversible on untreated, treated, and modified B-MWCNTs. Namely, the CVs of $\left[\mathrm{Fe}(\mathrm{CN})_{6}\right]^{3-/ 4-}$ on studied B-MWCNTs composite films are quite symmetric with ratio of oxidation and reduction peak current equal to unity and independent of scan rate. This behavior demonstrates that there is no parallel chemical reaction coupled to electron transfer and that the redox system $\left[\mathrm{Fe}(\mathrm{CN})_{6}\right]^{3-/ 4-}$ is stable in time frame of experiment confirming that the charge-transfer process is reversible. 
The effect of scan rate on oxidation and reduction peaks was also studied. As was expected, with increasing scan rate, a slight shift of oxidation and reduction peaks to more and less positive potentials, respectively, occurs, and thus, $\Delta E_{\mathrm{p}}$ tends to increase with increasing scan rate as result of uncompensated resistance effect [38]. In addition, the oxidation and reduction peak currents of $\left[\mathrm{Fe}(\mathrm{CN})_{6}\right]^{3-14-}$ on studied B-MWCNTs composite films change linearly with the square root of scan rate indicating that the electrochemical process is diffusion controlled. The last result is another evidence of the reversibility of $\left[\mathrm{Fe}(\mathrm{CN})_{6}\right]^{3-14-}$ redox system on untreated, acid and oxidative treated and AuNPs-modified B-MWCNTs.

The anodic and cathodic peak potential separation of $\left[\mathrm{Fe}(\mathrm{CN})_{6}\right]^{3-14-}$ estimated at the lowest concentration (where the uncompensated resistance effect is insignificant) on BMWCNTs $\quad\left(\Delta E_{\mathrm{p}} \approx 0.116 \mathrm{~V}\right), \quad$ B-MWCNTs/HCl $\quad\left(\Delta E_{\mathrm{p}} \approx 0.101 \quad \mathrm{~V}\right), \quad$ B-MWCNTs/Piranha $\left(\Delta E_{\mathrm{p}} \approx 0.080 \mathrm{~V}\right)$, and B-MWCNTs/AuNPs $\left(\Delta E_{\mathrm{p}} \approx 0.071 \mathrm{~V}\right)$ appears to be slightly greater compared to $\Delta E_{\mathrm{p}} \approx 0.059 \mathrm{~V}$ [39], which is expected for reversible one-electron transfer redox process. In addition $\Delta E_{\mathrm{p}}$ dependents strongly on concentration of redox species, namely $\Delta E_{\mathrm{p}}$ increases with concentration of $\left[\mathrm{Fe}(\mathrm{CN})_{6}\right]^{3-/ 4-}$. This observation can be attributed to uncompensated resistance effect [33]. However, the observed tendency of diminishing of $\Delta E_{\mathrm{p}}$ demonstrates that the treatment and decoration of carbon nanotubes result to an enhancement of their electrocatalytic activity. In addition, the smallest $\Delta E_{\mathrm{p}}$ value estimated for BMWCNTs/AuNPs $\left(\Delta E_{\mathrm{p}} \approx 0.071 \mathrm{~V}\right)$ reveals that the kinetic of redox system is quite enhanced on this particular composite film.

The heterogeneous electron transfer rate constant $\left(k_{\mathrm{s}}\right)$ of $\left[\mathrm{Fe}(\mathrm{CN})_{6}\right]^{3-/ 4-}$ on untreated, treated, and modified B-MWCNTs was estimated by means of electrochemical absolute rate relation that connects $k_{\mathrm{s}}$ with $\Delta E_{\mathrm{p}}$ through a working curve of dimensionless kinetic parameter $\psi$ [40]. The calculated $k_{\mathrm{s}}$ values are included in Table 2 . The findings reveal that the kinetics of redox process occurring onto either treated or modified B-MWCNTs is faster compared to that taking place onto untreated B-MWCNTs. It is interesting that the $k_{\mathrm{s}}$ parameter of $\left[\mathrm{Fe}(\mathrm{CN})_{6}\right]^{3-/ 4-}$ system tends to increase with the following order: B-MWCNTs $<$ B-MWCNTs/HCl $<$ BMWCNTs/Piranha < B-MWCNTs/AuNPs. The extracted results confirm that the acid and oxidative treatment as well as the modification of nanotubes with AuNPs improves the kinetics of redox process occurring onto carbon nanotubes. It can be also concluded that the surface modification of carbon nanotubes with AuNPs leads to a particular improvement of kinetics of electron transfer. This observation can be connected to differences in degree of structural defects of carbon nanotubes. Namely, Raman analysis demonstrates greater degree of defects for treated and modified B-MWCNTs. In literature a relationship between the Raman spectra 
of carbon materials and their activity in electron transfer processes was reported [41,42]. A correlation between the "disorder" Raman D band of carbon and electron-transfer kinetics for redox systems was observed. Namely, it was reported that the graphitic edges associated with disorder are important to fast electron transfer [43].

In order to estimate the lower limit of detection of various studied B-MWCNTs composite films towards $\left[\mathrm{Fe}(\mathrm{CN})_{6}\right]^{3-/ 4-}$, the variation of oxidation peak current with the concentration of redox system was examined. The findings reveal that the untreated, treated, and modified B-MWCNTs exhibit linear voltammetric response towards $\left[\mathrm{Fe}(\mathrm{CN})_{6}\right]^{3-14-}$ in the investigated concentration range of $0.099-0.990 \mathrm{mM}$. Consequently, from the linear concentration-oxidation current dependence, the lower limits of detection and the sensitivities of B-MWCNTs composite films towards $\left[\mathrm{Fe}(\mathrm{CN})_{6}\right]^{3-14-}$ were estimated (Table 2). The findings demonstrate that the detection limit decreases, and thus the sensitivity of composite films increases with the following order: B-MWCNTs $<$ B-MWCNTs/HCl $<$ B-MWCNTs/Piranha $<$ B-MWCNTs/AuNPs. These results demonstrate that the surface modification of carbon nanotubes with AuNPs leads to an enhanced electrocatalytic activity and sensitivity towards studied redox system.

The electrochemical behavior of B-MWCNTs composite films in the presence of $\left[\mathrm{Fe}(\mathrm{CN})_{6}\right]^{3-/ 4-}$ was further studied by means of electrochemical impedance spectroscopy (EIS) technique. Representative EIS spectra recorded for $0.990 \mathrm{mM}\left[\mathrm{Fe}(\mathrm{CN})_{6}\right]^{3-/ 4-}(1.0 \mathrm{M} \mathrm{KCl})$ on untreated, treated, and modified B-MWCNTs are shown in Fig.5. The EIS spectra recorded for other concentrations of redox system were skipped, since no significant effect of concentration of $\left[\mathrm{Fe}(\mathrm{CN})_{6}\right]^{3-14-}$ on system impedance was observed. The EIS spectra are graphically presented as Nyquist plots, where the complex impedance of redox system is presented as the sum of real and imaginary impedance components. The equivalent electrical circuit used for the simulation of recorded EIS spectra is shown in Fig.S6 (ESM).

The EIS spectra exhibit that at high frequencies the impedance is controlled by interfacial electron transfer, while at low frequencies the Warburg impedance is generated. Namely, the EIS spectra include a depressed semicircle at high frequencies that corresponds to electron-transfer limiting process and a linear part at middle and low frequencies, which arises from diffusion limiting step of electrochemical process. The charge-transfer resistance $\left(R_{\mathrm{ct}}\right)$ is a quite suitable parameter for studying the interfacial properties of composite films, since it is related to electron-transfer kinetics of redox system at electrode interface, and it represents the barrier for electron-transfer process occurring onto electrode's surface. Specifically, $R_{\mathrm{ct}}$ represents the hindering behavior of interface properties of composite film [44]. The $R_{\mathrm{ct}}$ values 
resulted from the simulation of recorded EIS spectra are reported in Table 2. The charge transfer resistance estimated for $\left[\mathrm{Fe}(\mathrm{CN})_{6}\right]^{3-/ 4-}$ on untreated B-MWCNTs appears to be greater compared to that obtained on either acid and oxidative treated or AuNPs-modified B-MWCNTs. Namely, the $R_{\mathrm{ct}}$ values, and thus, the barrier for electron-transfer tend to decrease with the following order: B-MWCNTs > B-MWCNTs/HCl > B-MWCNTs/Piranha > B-MWCNTs/AuNPs. It is noticeable that the estimated $R_{\mathrm{ct}}$ values vary inversely with the $k_{\mathrm{s}}$ parameter, something which is in absolute agreement with previous studies reported in literature $[45,46]$. The results demonstrate the fewer barriers for electron transfer, and thus, the greater electrocatalytic activity of carbon nanotubes modified with AuNPs [47,48].

\subsection{Electrochemical response of B-MWCNTs/AuNPs towards oxidation of DA and EP}

Representative CVs recorded for various concentrations of DA and EP on BMWCNTs/AuNPs (PBS, pH 7.4) at the scan rate of $0.02 \mathrm{~V} \cdot \mathrm{s}^{-1}$ are shown in Fig.6a and Fig.6b, respectively.

As it can be seen in CVs shown in Fig.6a the oxidation and reduction peaks of DA on B-MWCNTs/AuNPs occur at about $E_{\mathrm{p}}{ }^{\mathrm{ox}} \approx 0.203 \mathrm{~V}(v s . \mathrm{Ag} / \mathrm{AgCl})$ and $E_{\mathrm{p}}{ }^{\text {red }} \approx 0.161 \mathrm{~V}$ (vs. $\mathrm{Ag} / \mathrm{AgCl}$ ), respectively. A slight shift of oxidation and reduction peaks to more anodic and less anodic (positive) potentials, respectively, with the increase of the concentration of redox system was observed that can be attributed to the uncompensated resistance of the cell setup (IR drop) between the working electrode and the reference electrode. According to literature reports, the reversible oxidation of DA can be characterized as two-electron and two-proton transfer process leading to the formation of dopamine-o-quinone (DAQ) (Fig.S7a; ESM) [49].

DA shows on B-MWCNTs/AuNPs relative small peak-to-peak separation of around 42 $\mathrm{mV}$ indicating fast electron transfer at this particular electrode. It is interesting to mention that the oxidation and reduction of DA on unmodified B-MWCNTs occurs at about $E_{\mathrm{p}}{ }^{\text {ox }} \approx 0.226$ and $E_{\mathrm{p}}{ }^{\text {red }} \approx 0.159 \mathrm{~V}$ (vs. $\mathrm{Ag} / \mathrm{AgCl}$ ), respectively (and consequently $\Delta E_{p} \approx 0.067 \mathrm{~V}$ ) demonstrating a restricted in some degree reversibility of DA on undecorated B-MWCNTs film. Besides, it was also observed that the redox current of DA on B-MWCNTs/AuNPs is higher than that on BMWCNTs film. The findings demonstrate once more that B-MWCNTs/AuNPs has greater electrocatalytic activity for oxidation of DA compared to unmodified B-MWCNTs. The superior electrocatalytic activity of B-MWCNTs/AuNPs is mainly ascribed to the synergic effect of AuNPs and carbon nanotubes. Excepting that carbon nanotubes with high proportion of edge plan sites support and amplify the electrocatalytic oxidation of DA, AuNPs can further improve the electrocatalytic activity of modified composite film since they can provide better 
electric linkage between electrode active sites and DA [50]. Deng et al. [51] reported that the surface of AuNPs may be partially oxidized and the formed gold oxide nanoparticles can be served as mediator for the improvement of electrocatalytic ability of composite film for oxidation of DA.

EP demonstrates an irreversible behavior on B-MWCNTs/AuNPs film. Namely, in CVs recorded for EP on B-MWCNTs/AuNPs composite film an anodic and cathodic peaks around

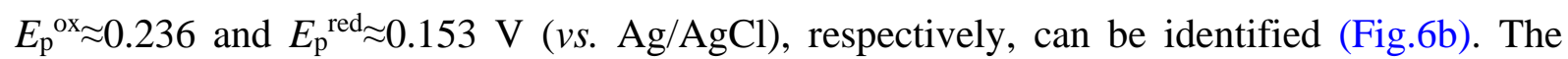
reverse-to-forward peak current ratio $\left(I_{\mathrm{red}} / I_{\mathrm{ox}}\right)$ is significantly less than unity indicating that probably a chemical reaction is coupled to electron transfer process resulting to irreversible charge transfer process. According to literature reports, the anodic peak is due to oxidation of EP to open-chain epinephrine-o-quinone (EPQ), and the cathodic peak is attributed to reduction of EPQ to EP (two-electron coupled with two-proton transfer process) (Fig.S7b; ESM) [52,53]. It must be mentioned that additional anodic and cathodic peaks can be seen in CVs recorded in negative potential region (this potential region is not displayed in CVs) that are attributed to adrenochrome / leucoadrenochrome redox system that arises upon cyclization of EP [54]. Since oxidation of DA $\left(E_{\mathrm{p}}{ }^{\mathrm{ox}} \approx 0.203 \mathrm{~V}\right.$ vs. $\left.\mathrm{Ag} / \mathrm{AgCl}\right)$ and $\mathrm{EP}\left(E_{\mathrm{p}}{ }^{\mathrm{ox}} \approx 0.236\right.$ s. $\left.\mathrm{Ag} / \mathrm{AgCl}\right)$ occurs in the same potential region, interference of DA in sensitive detection of $\mathrm{EP}$, and the inverse, interference of EP in analysis of DA, can be expected. Thus, CVs recorded for various concentration ratios of DA/EP binary system exhibited overlapped oxidation waves of analytes (Fig.S8; ESM).

From the linear variation of oxidation peak currents of DA and EP with their concentration in the range of $0.323-1.020 \mathrm{mM}$ (Figs.6c-d) the lower limits of detection (LOD) and limits of quantification $(L O Q)$ of B-MWCNTs/AuNPs composite film towards DA/DAQ $(L O D=0.20 \mu \mathrm{M} ; L O Q=0.67 \mu \mathrm{M})$ and $\mathrm{EP} / \mathrm{EPQ}(L O D=0.30 \mu \mathrm{M} ; L O Q=1.50 \mu \mathrm{M})$ redox systems were estimated by means of linear regression method. For comparison reasons, the $L O D$ values are presented in Table S1 (ESM) along with available $L O D$ values reported in literature for other novel composite films. As it can be seen in Table S1 (ESM) in comparison to other carbon-based composite films the B-MWCNTs/AuNPs exhibits favorable electroanalytical response towards DA and EP.

Interference studies with potential interfering substances were additionally carried out on B-MWCNTs/AuNPs composite film. It is well known that the main problem of measuring DA and EP in vivo is the interference effect caused by large excesses of interfering substances, such as ascorbic acid (AA) and uric acid (UA). Unfortunately, at the most of conventional electrodes, such as glassy carbon, platinum, gold electrodes, AA and UA are oxidized at 
potential very close to oxidation potentials of DA and EP resulting therefore in overlapping voltammetric response of analytes. Thus, interference effects in analysis of DA and EP can be observed under coexistence of AA and UA on these particular electrodes. The findings demonstrate that AA and UA do not interfere with the analysis of either DA or EP on BMWCNTs/AuNPs composite film. Namely, the irreversible oxidation of AA onto BMWCNTs/AuNPs occuring around $E_{\mathrm{p}}{ }^{\text {ox }} \approx 0.02 \mathrm{~V}$ (vs. $\mathrm{Ag} / \mathrm{AgCl}$ ) lies at about 180 and $215 \mathrm{mV}$ less anodic potential compared to oxidation wave of DA and EP, respectively. In addition, the irreversible oxidation wave of UA that appears at $E_{\mathrm{p}}{ }^{\text {ox }} \approx 0.38 \mathrm{~V}$ (vs. $\mathrm{Ag} / \mathrm{AgCl}$ ) was shifted to more anodic potential compared to oxidation waves of DA and EP (about 175 and $140 \mathrm{mV}$, respectively). It is, thus, obvious that the oxidation peak separations between DA or EP and the potentially interfering substances (AA and UA) are large, and therefore, the electrochemical analysis of DA and EP in the presence of either AA or UA can be carried out. Interference studies with other potential interfering substances such as glucose (GL), acetaminophen (AC), and $N$-acetylcysteine (NAC) were also carried out. In CVs recorded for DA/GL and EP/GL no anodic peak corresponding to oxidation of GL was identified. It is evident that GL cannot be oxidized in the absence of its enzyme onto B-MWCNTs/AuNPs composite film, and thus, no interference effects are expected in analysis of DA and EP (Fig.S9; ESM). Furthermore, interference studies demonstrate that the oxidation waves of $\mathrm{AC}\left(E_{\mathrm{p}}{ }^{\mathrm{ox}} \approx 0.39 \mathrm{~V}\right.$ vs. $\left.\mathrm{Ag} / \mathrm{AgCl}\right)$

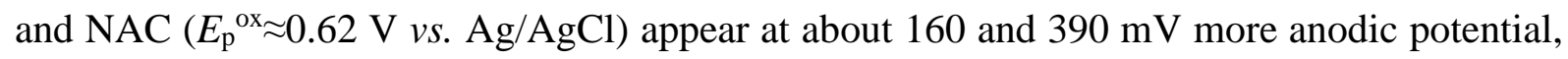
respectively, compared to DA and EP. Thus, AC and NAC have nearly no interference for the determination of either DA or EP. Representative CVs recorded for DA in the presence of AA, UA, AC, and NAC are shown in Figs.S10 and S11 (ESM).

\subsection{Analysis of DA and EP in presence of UA in biological sample}

The applicability of fabricated B-MWCNTs/AuNPs composite film for determination of DA and EP in biological samples was attempted. For this purpose the B-MWCNTs/AuNPs composite film was applied for electrochemical sensing for DA and EP in pig blood serum by means of $\mathrm{CV}$ technique. To fit into the linear range and reduce the matrix effect, the pig blood serum samples were diluted with PBS ( $\mathrm{pH}$ 7.4) before analysis without further pretreatments. The quantitative analysis of DA and EP was carried out by means of standard addition method. Namely, known amounts of DA and EP were added to a known volume of pig blood serum (PBS, pH 7.4) and the percentage recoveries were calculated. The calibration graphs obtained for different concentrations of DA and EP in PBS ( $\mathrm{pH}$ 7.4) (Figs.6c-d) were used for the determination of added analytes in pig blood serum. Representative CVs recorded for three 
different additions of DA and EP in pig blood serum are shown in Figs.7a-b. The detection results in blood serum samples are listed in Table S2 (ESM). The percentage recovery in blood serum samples determined was in the ranges of $97.5-101.7 \%$ and $97.3-102.5 \%$ for DA and EP, respectively. The recovery values demonstrate that the analysis of DA and EP on BMWCNTs/AuNPs in blood serum is effective, accurate and very reproducible. According to these results, the B-MWCNTs/AuNPs composite film is quite reliable and sensitive and can be successfully applied to determine DA and EP in real biological samples.

The effect of interference of UA in analysis of DA and EP was also investigated in pig blood serum. The CVs recorded for UA in presence of DA and EP onto B-MWCNTs/AuNPs reveal that the irreversible oxidation peak of UA appears around $E_{\mathrm{p}}{ }^{\mathrm{ox}} \approx 0.38 \mathrm{~V}$ (vs. $\left.\mathrm{Ag} / \mathrm{AgCl}\right)$ (Figs.7c-d) that lies at about 175 and $140 \mathrm{mV}$ more anodic (positive) potential compared to oxidation peaks of DA and EP, respectively. In previous published studies it was suggested that this oxidation peak can be attributed to primary two electron oxidation of UA to uric acid diimine (UAD) (Fig.S7c; ESM) [55]. It is remarkable that the oxidation peaks of DA-UA and EP-UA couples are still well separated (not overlapped) in excess levels of UA (concentration ratios of DA-UA and EP-UA around 1:20). These findings exhibit that the simultaneous electrochemical analysis of DA-UA (in absence of EA) and EP-UA (in absence of DA) can be carried out in blood serum on B-MWCNTs/AuNPs in a single measurement.

\section{Conclusions}

B-MWCNTs were fabricated with decomposition of TEB and EtOH in presence of $\mathrm{FeCp}_{2}$ and were treated with hydrochloric acid and "piranha" solution, as well as were decorated with AuNPs. The untreated, acid and oxidative treated and AuNPs-modified B-MWCNTs were initially characterized using SEM and TEM techniques. B-MWCNTs possess asymmetric Yshaped structure due to defects along the axis of nanotubes that result from reduction of local hexagonal symmetry caused with boron-doping of carbon nanotubes. The influence of acid and oxidative treatment as well as the modification of B-MWCNTs with AuNPs on degree of defects of carbon nanotubes was investigated by means of Raman spectroscopy. The findings exhibit an enhancement of degree of defects of carbon nanotubes upon their treatment with hydrochloric acid, "piranha" solution or their decoration with AuNPs. Electrochemical investigation of various B-MWCNTs composite films towards $\left[\mathrm{Fe}(\mathrm{CN})_{6}\right]^{3-/ 4-}$ demonstrates that upon acid and oxidative treatment as well as with the decoration of B-MWCNTs with AuNPs the electrochemical response and sensitivity of carbon nanotubes tends to be much better. However, it is noticeable that an enhanced electrochemical response and sensitivity can be 
recognized for B-MWCNTs/AuNPs. This observation is attributed to AuNPs that improve the electrocatalytic activity of composite film by providing electric linkage between electrode active sites and redox systems. The electrochemical analysis of DA and EP either individually or in presence of an excess of UA was successfully carried onto B-MWCNTs/AuNPs in pig blood serum (PBS, pH 7.4). The findings demonstrate that B-MWCNTs/AuNPs is a promising sensor material for simultaneous electrochemical analysis of DA and EP in presence of UA in biological samples.

Acknowledgments: The authors would like to thank Mrs. Doreen Schneider (Ilmenau University of Technology). The SEM/EDX and TEM/EDX analyses were carried out at Advanced Microscopy Laboratory (Trinity College Dublin, Ireland) with the financial support of European Commission (QualityNano; Grant Agreement No. FP7-262163; Application TCDTAF-436).

Table 1 Raman D-bands, G-bands, and intensity ratios of Raman G- and D-bands $\left(I_{\mathrm{D}} / I_{\mathrm{G}}\right)$ for untreated, acid and oxidative treated and AuNPs-modified B-MWCNTs

\begin{tabular}{cccc}
\hline Composite film & $v_{\mathrm{D}} / \mathrm{cm}^{-1}$ & $v_{\mathrm{G}} / \mathrm{cm}^{-1}$ & $I_{\mathrm{D}} / I_{\mathrm{G}}$ \\
\hline B-MWCNTs & 1439.10 & 1538.85 & 0.51 \\
B-MWCNTs/HCl & 1439.10 & 1540.68 & 1.13 \\
B-MWCNTs/Piranha & 1439.09 & 1539.18 & 0.96 \\
B-MWCNTs/AuNPs & 1439.09 & 1539.84 & 1.04 \\
\hline
\end{tabular}


Table 2 Electrochemical parameters determined for $0.500 \mathrm{mM}\left[\mathrm{Fe}(\mathrm{CN})_{6}\right]^{3-14-}(1.0 \mathrm{M} \mathrm{KCl})$ on untreated, acid and oxidative treated and AuNPs-modified B-MWCNTs at $0.02 \mathrm{~V} \cdot \mathrm{s}^{-1}$

\begin{tabular}{lcccccc}
\hline \multicolumn{1}{c}{ Composite film } & $\begin{array}{c}E_{1 / 2} / \\
\mathrm{V}\end{array}$ & $\begin{array}{c}\Delta E_{\mathrm{p}} / \\
\mathrm{V}\end{array}$ & $\begin{array}{c}10^{3} k_{\mathrm{s}} / \\
\mathrm{cm} \cdot \mathrm{s}^{-1(\mathrm{a})}\end{array}$ & $\begin{array}{c}R_{\mathrm{ct}} / \\
\Omega^{(\mathrm{b})}\end{array}$ & $\begin{array}{c}L O D / \\
\mu \mathrm{M}^{(\mathrm{c})}\end{array}$ & \begin{tabular}{c}
$\mathrm{A} \cdot \mathrm{M}^{-1} \cdot \mathrm{cm}^{-2(\mathrm{c})}$ \\
\hline B-MWCNTs
\end{tabular} \\
\hline B-MWCNTs/HCl & 0.275 & 0.116 & 1.3 & 27 & 0.90 & 0.342 \\
B-MWCNTs/Piranha & 0.275 & 0.101 & 2.7 & 20 & 0.80 & 0.404 \\
B-MWCNTs/AuNPs & 0.275 & 0.080 & 8.6 & 15 & 0.60 & 0.508 \\
\hline
\end{tabular}


${ }^{(\mathrm{a})} k_{\mathrm{s}}$ was determined by electrochemical absolute rate relation: $\psi=\left(D_{\mathrm{o}} / D_{\mathrm{R}}\right)^{\mathrm{a} / 2} k_{\mathrm{s}}\left(n \pi F v D_{\mathrm{o}} / R T\right)^{-1 / 2}$, where $\psi$ is kinetic parameter, $a$ charge-transfer coefficient $(a \approx 0.5), D_{\mathrm{o}}$ and $D_{\mathrm{R}}$ diffusion coefficients of oxidized and reduced species, respectively $\left(D_{\mathrm{o}} \approx D_{\mathrm{R}}\right)$, and $n$ number of electrons involved in redox reaction [56]; ${ }^{(b)}$ The EIS spectra were analyzed by means of equivalent electrical circuit $\left(R_{\mathrm{S}}+\left(C_{\mathrm{dl}} /\left(R_{\mathrm{ct}}+Z_{\mathrm{w}}\right)\right)\right)$ (software Thales, version 4.15) (Fig.S6) (ESM); ${ }^{(\mathrm{c})} L O D$ and $S$ values were estimated by means of linear regression model, which can be expressed as $L O D=\left[3 \times \sigma_{\mathrm{a}}\right] / S$, where $\sigma_{\mathrm{a}}$ is the standard deviation of electrochemical response of sensor and $S$ the slope of linear calibration curve (oxidation peak current versus concentration of redox system) [57,58]
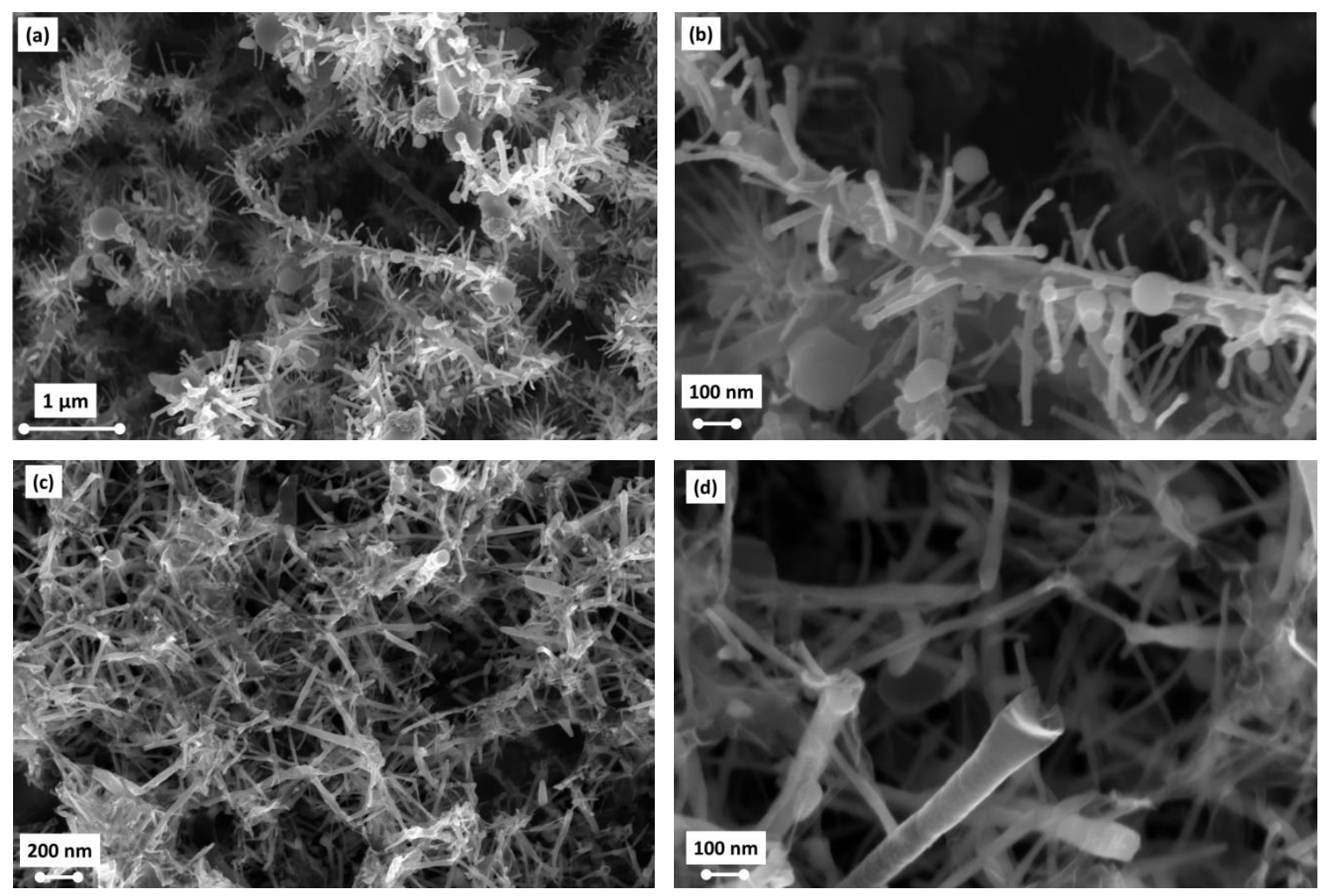

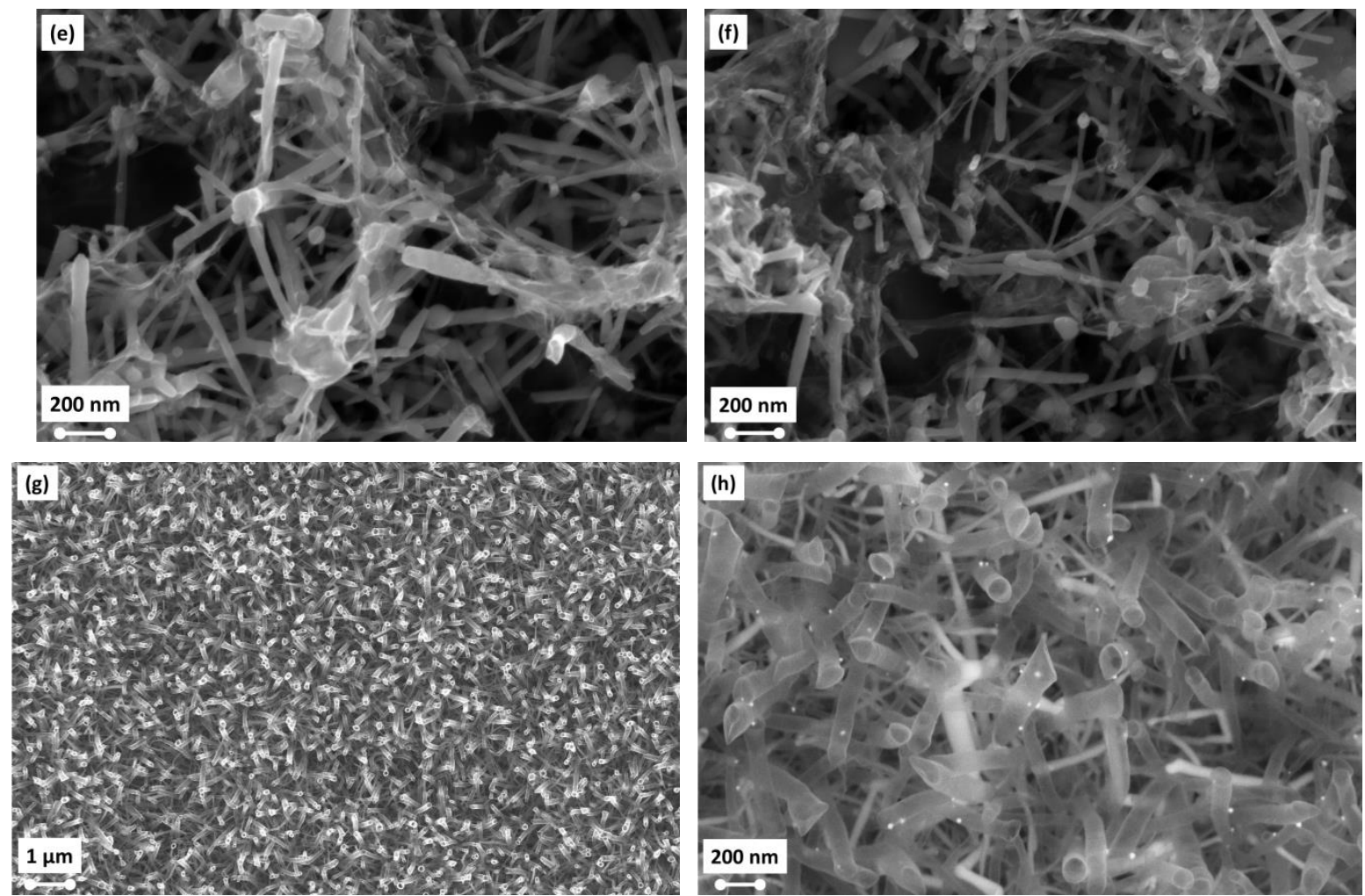

Fig.1 SEM images of untreated B-MWCNTs (a, b), B-MWCNTs/HCl (c, d), B-MWCNTs/

Piranha (e, f), and B-MWCNTs/AuNPs (g, h) composite films.
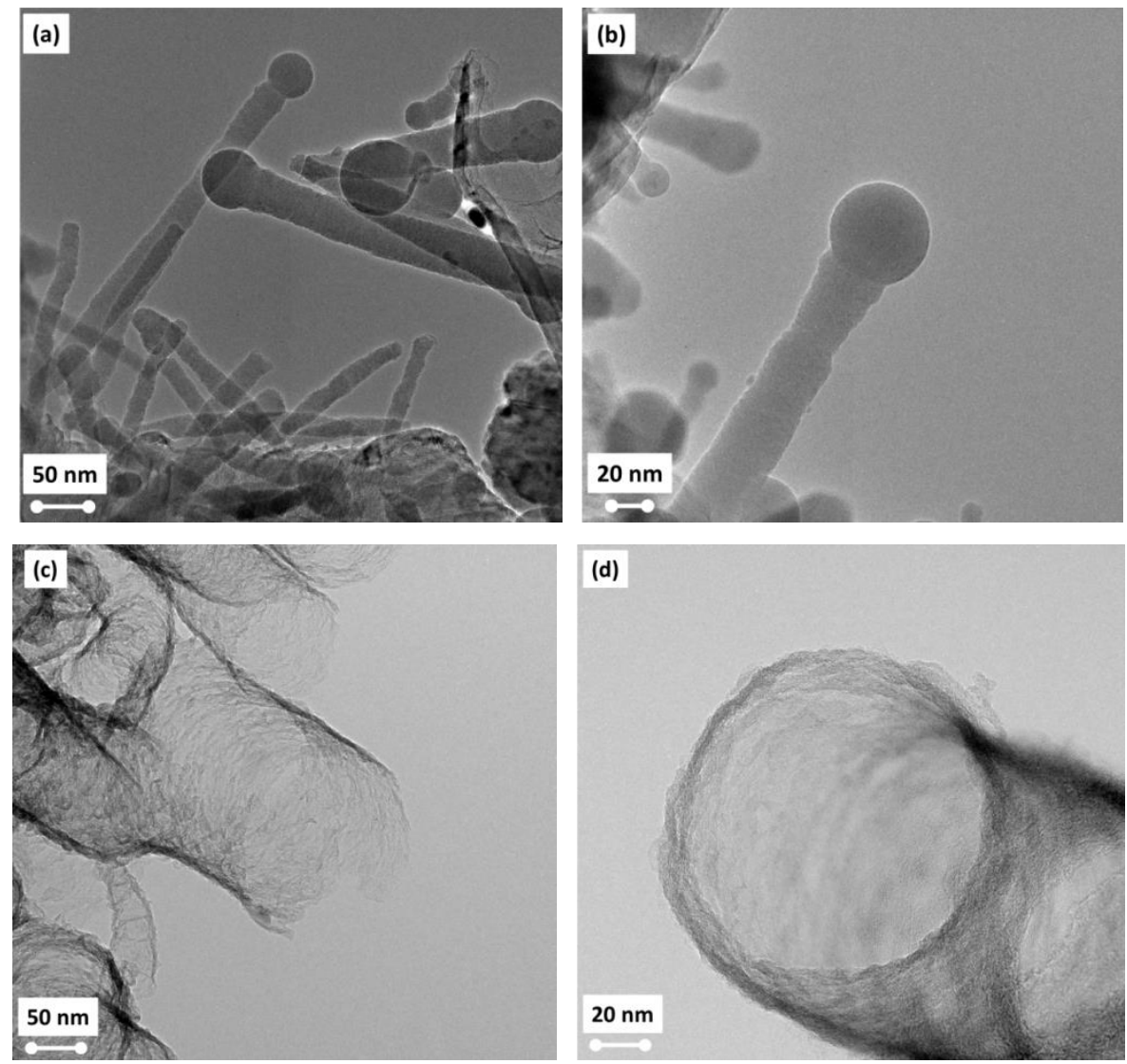

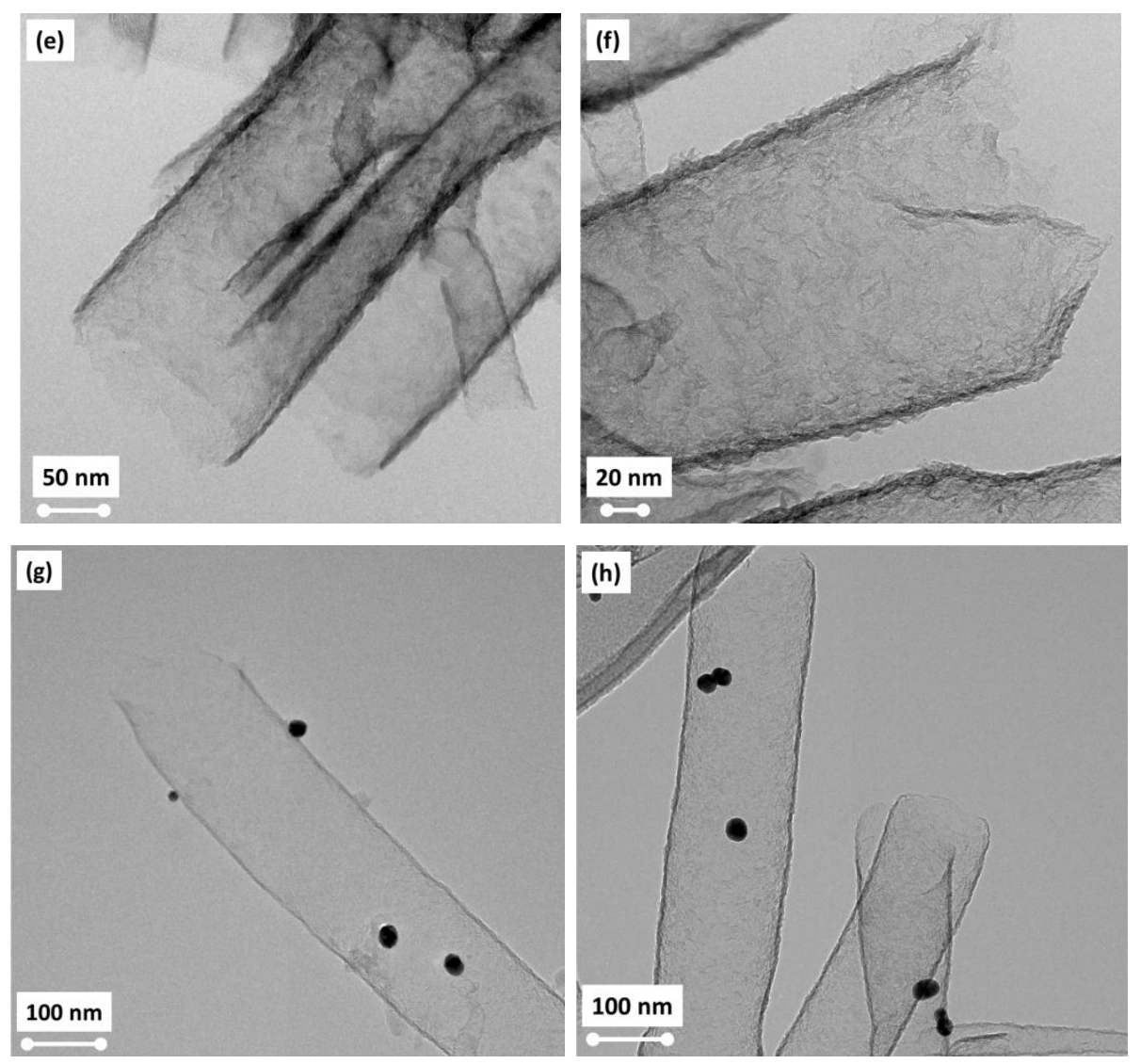

Fig.2 TEM images of untreated B-MWCNT (a, b), B-MWCNTs/HCl (c, d), B-MWCNTs/ Piranha (e, f), and B-MWCNTs/AuNPs $(\mathbf{g}, \mathbf{h})$ composite films.
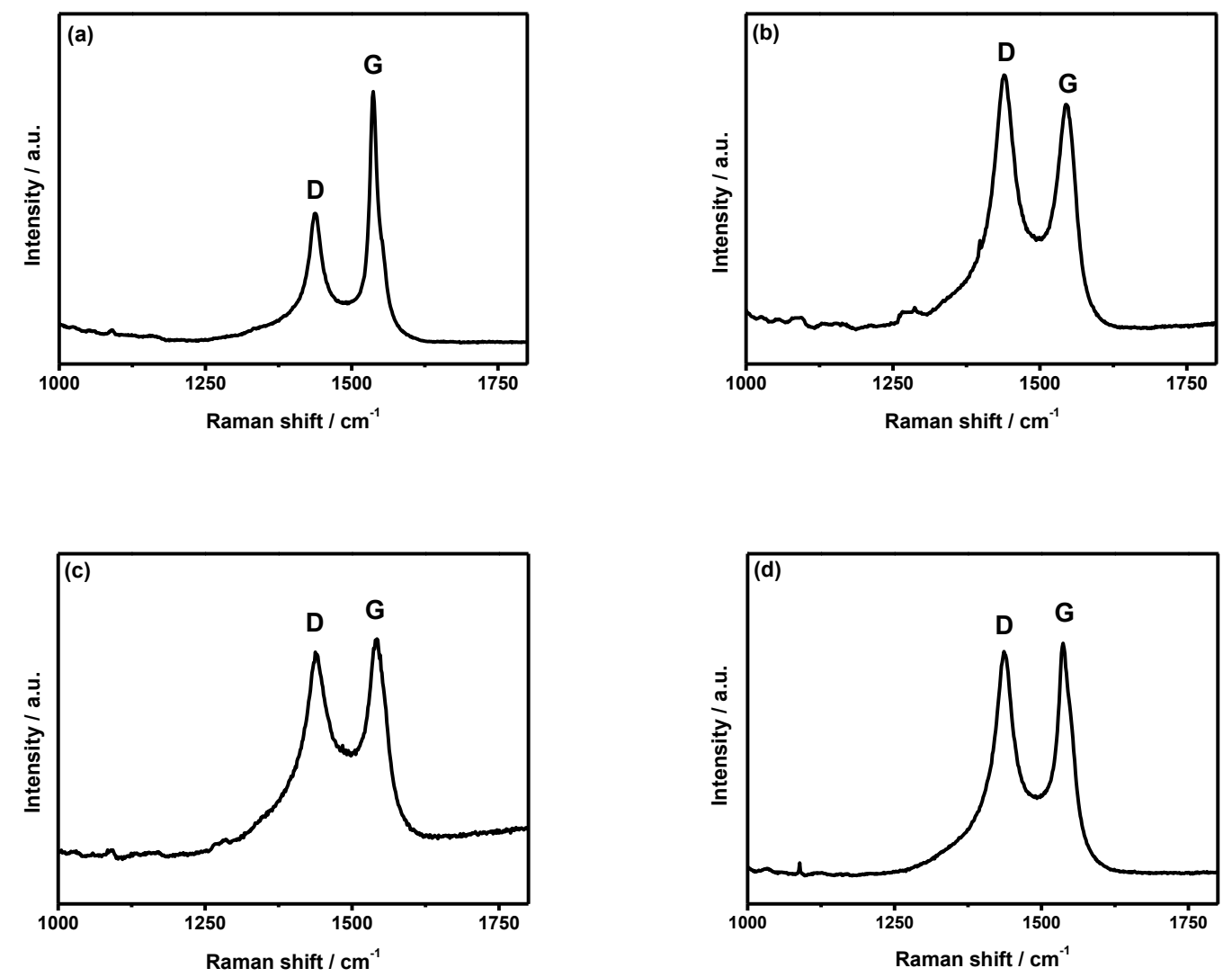
Fig.3 Raman spectra showing the $G$ and D-bands for untreated B-MWCNTs (a), BMWCNTs/HCl (b), B-MWCNTs/Piranha (c), and B-MWCNTs/AuNPs (d) composite films.
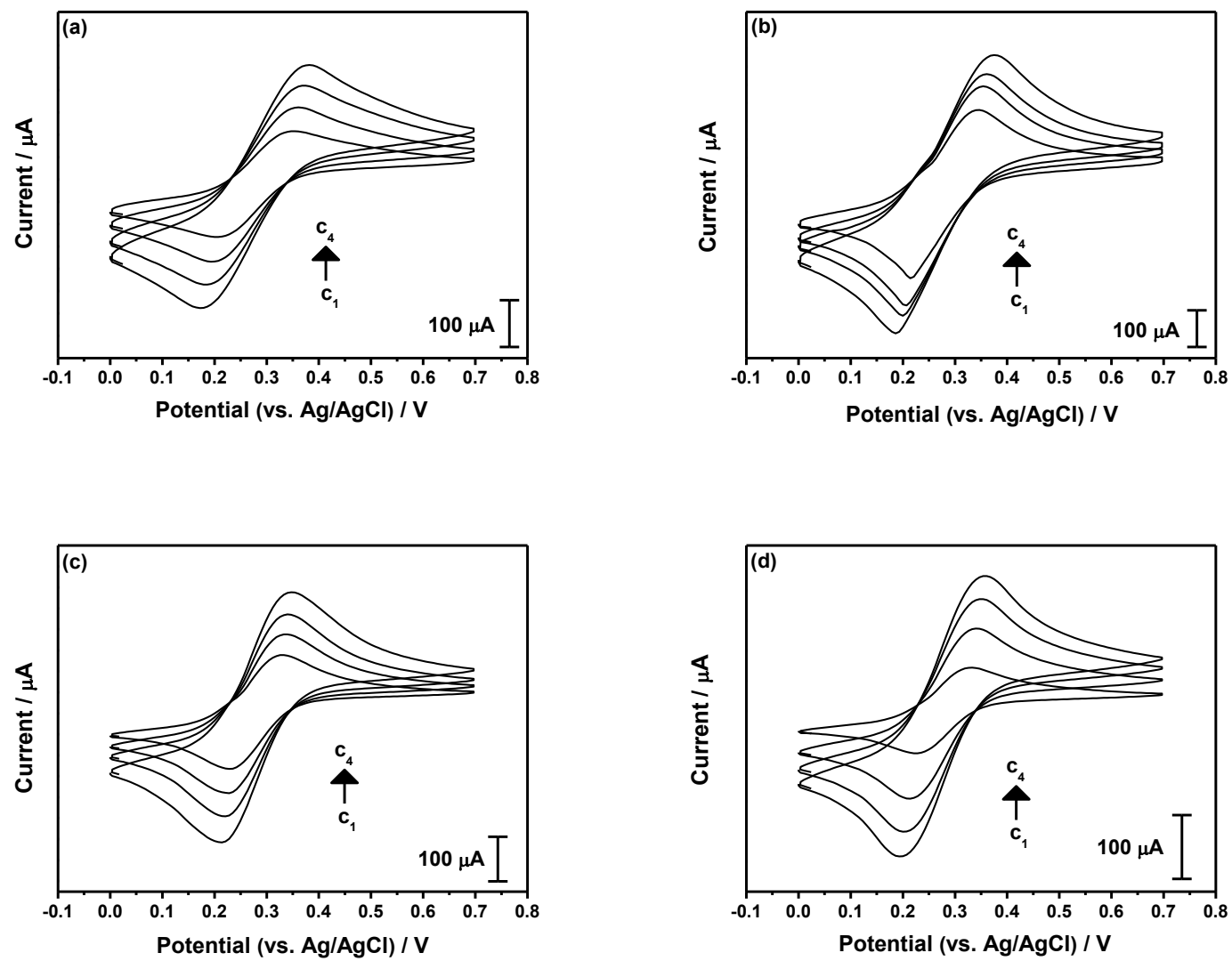

Fig.4 CVs recorded for various concentrations of $\left[\mathrm{Fe}(\mathrm{CN})_{6}\right]^{3-/ 4-}(1.0 \mathrm{M} \mathrm{KCl})$ on untreated BMWCNTs (a), B-MWCNTs/HCl (b), B-MWCNTs/Piranha (c), and B-MWCNTs/AuNPs (d) composite films at $0.02 \mathrm{~V} \cdot \mathrm{s}^{-1}$. The CVs (from inner to outer) correspond to the following concentrations: $c_{1}=0.196 \mathrm{mM} ; c_{2}=0.415 \mathrm{mM} ; c_{3}=0.595 \mathrm{mM} ; c_{4}=0.797 \mathrm{mM}$. 

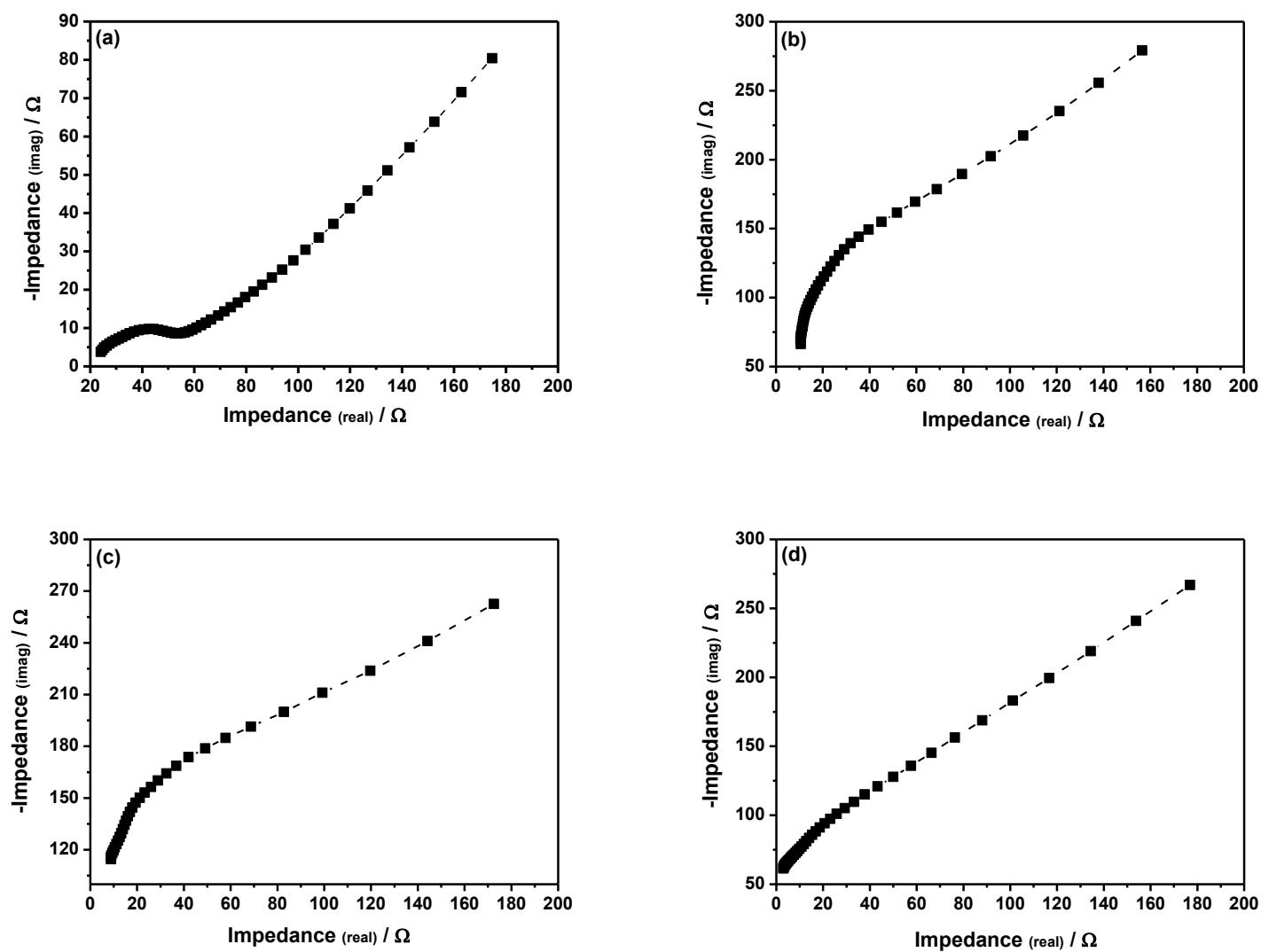

Fig.5 EIS spectra recorded for $0.990 \mathrm{mM}\left[\mathrm{Fe}(\mathrm{CN})_{6}\right]^{3-/ 4-}(1.0 \mathrm{M} \mathrm{KCl})$ on untreated B-MWCNTs (a), B-MWCNTs/HCl (b), B-MWCNTs/Piranha (c), and B-MWCNTs/AuNPs (d) composite films. 

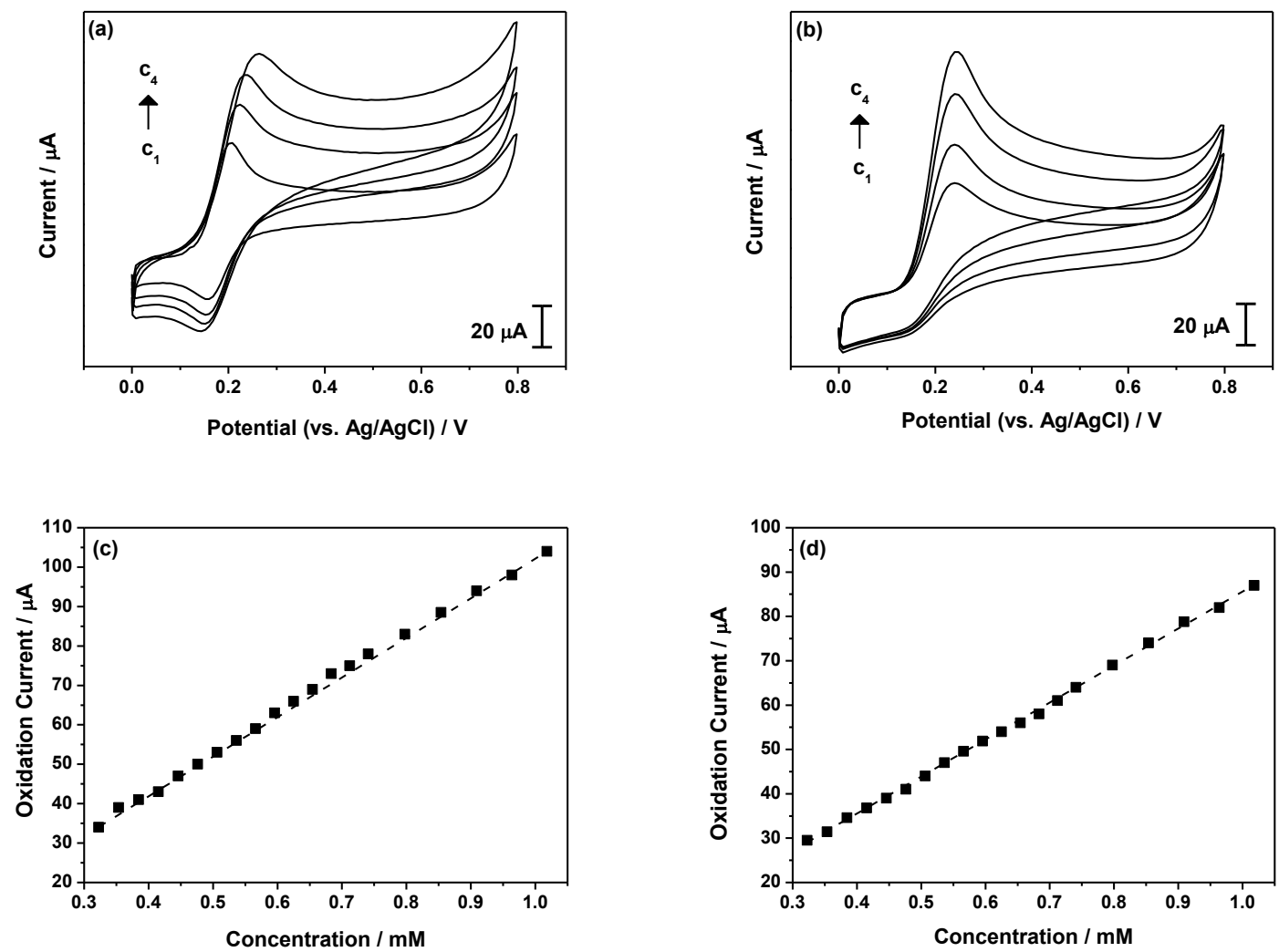

Fig.6 CVs recorded for various concentrations of DA (a) and EP (b) on B-MWCNTs/AuNPs at $0.02 \mathrm{~V} \cdot \mathrm{s}^{-1}$ (PBS, $\mathrm{pH}$ 7.4). The $\mathrm{CVs}$ (from inner to outer) correspond to following concentrations: $c_{1}=0.323 \mathrm{mM} ; c_{2}=0.683 \mathrm{mM} ; c_{3}=0.854 \mathrm{mM} ; c_{4}=1.020 \mathrm{mM} ;$ Variation of oxidation peak current of DA (c) and EP (d) with the concentration of analytes observed in CVs recorded on B-MWCNTs/AuNPs at $0.02 \mathrm{~V} \cdot \mathrm{s}^{-1}(\mathrm{PBS}, \mathrm{pH} 7.4)$. 

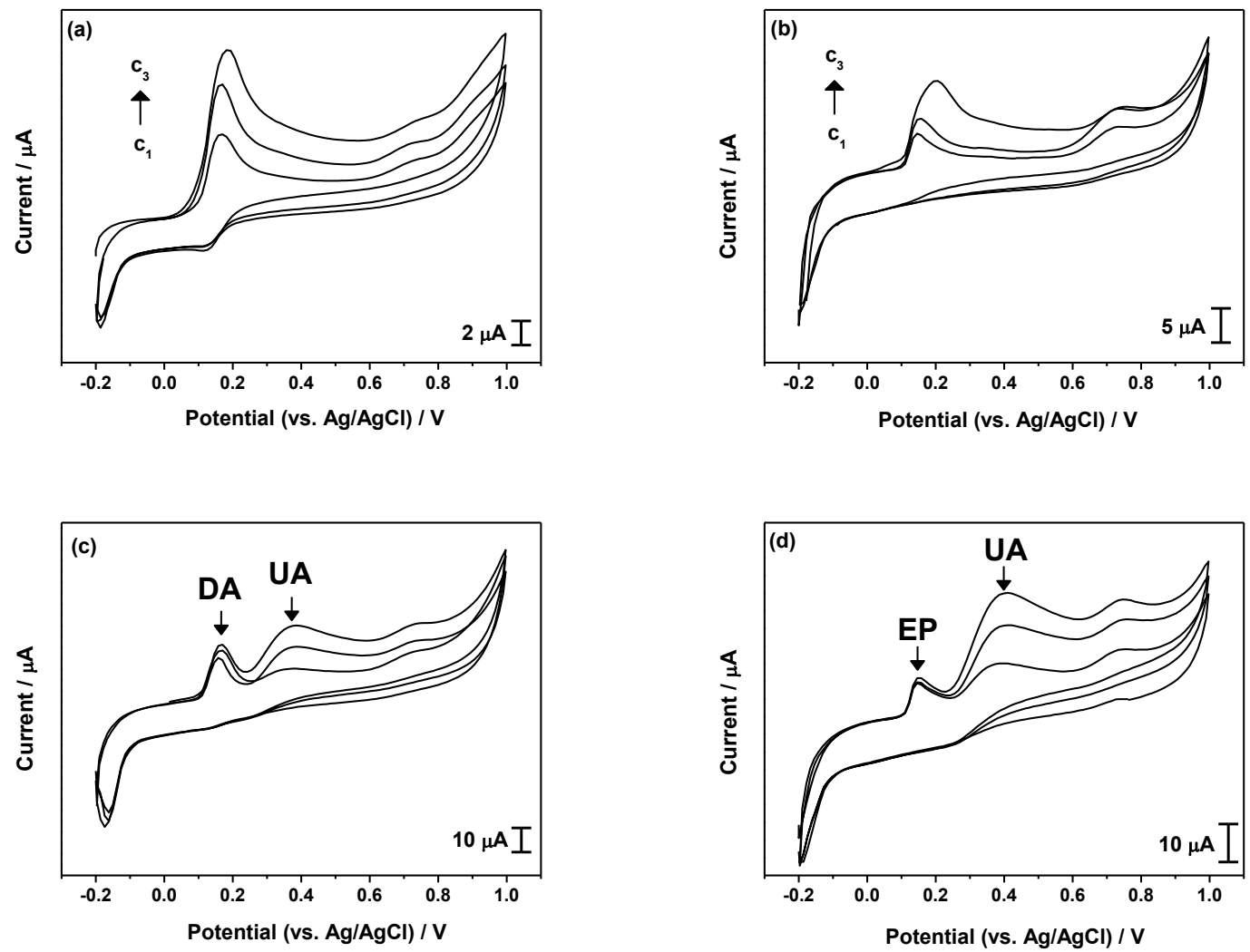

Fig.7 CVs recorded on B-MWCNTs/AuNPs at $0.02 \mathrm{~V} \cdot \mathrm{s}^{-1}$ after additions of proper amounts of DA (a) and EP (b) in pig blood serum (PBS, pH 7.4). The followings additions were done: (a) $c_{1}: 55 \mu \mathrm{M} ; c_{2}: 115 \mu \mathrm{M} ; c_{3}: 154 \mu \mathrm{M}$ (DA); (b) $c_{1}: 96 \mu \mathrm{M} ; c_{2}: 186 \mu \mathrm{M} ; c_{3}: 276 \mu \mathrm{M}$ (EP); CVs recorded on B-MWCNTs/AuNPs at $0.02 \mathrm{~V} \cdot \mathrm{s}^{-1}$ after additions of proper amounts of UA in DA (c) and EP (d) in pig blood serum (PBS, pH 7.4). 


\section{References}

[1] A.A. Koós, F. Dillon, E.A. Obraztsova, A. Crossley, N. Grobert, Comparison of structural changes in nitrogen and boron-doped multi-walled carbon nanotubes, Carbon 48 (2010) 30333041 .

[2] M.A. Mamo, A.O. Sustaita, Z.N. Tetana, N.J. Coville, I.A. Hümmelgen, Undoped, nitrogendoped and boron-doped multi-walled carbon nanotube/poly(vinyl alcohol) composite as active layer in simple hydrostatic pressure sensors, J. Mater. Sci. Mater. Electron. 24 (2013) 39954000 .

[3] R. Czerw, P.W. Chiu, Y.M. Choi, D.S. Lee, D.L. Carroll, S. Roth, Y.W. Park, Substitutional boron-doping of carbon nanotubes, Curr. Appl. Phys. 2 (2002) 473-477.

[4] S. Shiraishi, M. Kibe, T. Yokoyama, H. Kurihara, N. Patel, A. Oya, Y. Kaburagi, Y. Hishiyama, Electric double layer capacitance of multi-walled carbon nanotubes and B-doping effect, Appl. Phys. A 82 (2006) 585-591.

[5] Y.A. Kim, S. Aoki, K. Fujisawa, Y.I. Ko, K.S. Yang, C.M. Yang, Y.C. Jung, T. Hayashi, M. Endo, M. Terrones, M.S. Dresselhaus, Defect-assisted heavily and substitutionally borondoped thin multi-walled carbon nanotubes using high-temperature thermal diffusion, J. Phys. Chem. C 118 (2014) 4454-4459.

[6] W. Han, Y. Bando, K. Kurashima, T. Sato, Boron-doped carbon nanotubes prepared through a substitution reaction, Chem. Phys. Lett. 299 (1999) 368-373.

[7] D. Golberg, Y. Bando, W. Han, K. Kurashima, T. Sato, Single-walled B-doped carbon, B/Ndoped carbon and $\mathrm{BN}$ nanotubes synthesized from single-walled carbon nanotubes through a substitution reaction, Chem. Phys. Lett. 308 (1999) 337-342.

[8] Y. Sato, H. Nishizaka, K. Motomiya, G. Yamamoto, A. Okubo, H. Kimura, M. Ishikuro, K. Wagatsuma, T. Hashida, K. Tohji, Boron-assisted transformation to rod-like graphitic carbons 
from multi-walled carbon nanotubes in boron-mixed multi-walled carbon nanotube solids, ACS Appl. Mater. Interfaces 3 (2011) 2431-2439.

[9] J.L. Blackburn, Y. Yan, C. Engtrakul, P.A. Parilla, K. Jones, T. Gennett, A.C. Dillon, M.J. Heben, Synthesis and characterization of boron-doped single-wall carbon nanotubes produced by the laser vaporization technique, Chem. Mater. 18 (2006) 2558-2566.

[10] B.G. Sumpter, V. Meunier, J.M. Romo-Herrera, E. Cruz-Silva, D.A. Cullen, H. Terrones, D.J. Smith, M. Terrones, Nitrogen-mediated carbon nanotube growth: diameter reduction, metallicity, bundle dispersability, and bamboo-like structure formation, ACS Nano 1 (2007) 369-375.

[11] B.G. Sumpter, J. Huang, V. Meunier, J.M. Romo-Herrera, E. Cruz-Silva, H. Terrones, M. Terrones, A theoretical and experimental study on manipulating the structure and properties of carbon nanotubes using substitutional dopants, Int. J. Quantum Chem. 109 (2009) 97-118.

[12] W. Han, Y. Bando, K. Kurashima, T. Sato, Boron-doped carbon nanotubes prepared through a substitution reaction, Chem. Phys. Lett. 299 (1999) 368-373.

[13] P. Ayala, R. Arenal, A. Loiseau, A. Rubio, T. Pichler, The physical and chemical properties of heteronanotubes, Rev. Mod. Phys. 82 (2010) 1843-1885.

[14] T. Koretsune, S. Saito, Electronic structure of boron-doped carbon nanotubes, Phys. Rev. B 77 (2008) 165417.

[15] R.B. Sharma, D.J. Late, D.S. Joag, A. Govindaraj, C.N.R. Rao, Field emission properties of boron and nitrogen doped carbon nanotubes, Chem. Phys. Lett. 428 (2006) 102-108.

[16] N. Al-Aqtash, I. Vasiliev, Ab initio study of boron- and nitrogen-doped graphene and carbon nanotubes functionalized with carboxyl groups, J. Phys. Chem. C 115 (2011) 1850018510. 
[17] N. Murata, J. Haruyama, J. Reppert, A.M. Rao, T. Koretsune, S. Saito, M. Matsudaira, Y. Yagi, Superconductivity in thin films of boron-doped carbon nanotubes, Phys. Rev. Lett. 101 (2008) 27002.

[18] T. Hashitani, K. Mizukawa, M. Kumazaki, H. Nishino, Dopamine metabolism in the striatum of hemiparkinsonian model rats with dopaminergic grafts, Neurosci. Res. 30 (1998) 43-52.

[19] A. Carlsson, L.O. Hansson, N. Waters, M.L. Carlsson, Neurotransmitter aberrations in schizophrenia: new perspectives and therapeutic implications, Life Sci. 61 (1997) 75-94.

[20] N. Nakao, T. Itakura, Fetal tissue transplants in animal models of Huntington's disease: the effects on damaged neuronal circuitry and behavioral deficits, Prog. Neurobiol. 61 (2000) 313338.

[21] R. Trouillon, M.K. Passarelli, J. Wang, M.E. Kurczy, A.G. Ewing, Chemical analysis of single cells, Anal. Chem. 85 (2013) 522-542.

[22] E.S. Bucher, R.M. Wightman, Electrochemical analysis of neurotransmitters, Annu. Rev. Anal. Chem. 8 (2015) 239-261.

[23] N.G. Tsierkezos, U. Ritter, Synthesis and electrochemistry of multi-walled carbon nanotube films directly attached on silica substrate, J. Solid State Electrochem. 14 (2010) 11011107.

[24] N.G. Tsierkezos, U. Ritter, Oxidation of dopamine on multiwalled carbon nanotubes, J. Solid State Electrochem. 16 (2012) 2217-2226.

[25] N.G. Tsierkezos, N. Wetzold, U. Ritter, Electrochemical responses of carbon nanotubesbased films printed on polymer substances, Ionics 19 (2013) 335-341.

[26] J. Kimling, M. Maier, B. Okenve, V. Kotaidis, H. Ballot, A. Plech, Turkevich method for gold nanoparticle synthesis revisited, J. Phys. Chem. B 110 (2006) 15700-15707. 
[27] N.G. Tsierkezos, N. Wetzold, U. Ritter, A.C. Hübler, Analysis of dopamine on printed polymer thin film consisting of multiwalled carbon nanotubes, Monatsh. Chem. 144 (2013) 581-588.

[28] N.G. Tsierkezos, N. Wetzold, A.C. Hübler, U. Ritter, P. Szroeder, Multi-walled carbon nanotubes printed onto polycarbonate substrate for electrochemical sensing, Sens. Lett. 11 (2013) 1465-1471.

[29] D.L. Carroll, P. Redlich, X. Blase, J.C. Charlier, S. Curran, P.M. Ajayan, S. Roth, M. Rühle, Effects of nanodomain formation on the electronic structure of doped carbon nanotubes, Phys. Rev. Lett. 81 (1998) 2332-2335.

[30] I. Zsoldos, G. Kakuk, T. Réti, A. Szasz, Geometric construction of carbon nanotube junctions, Model Simul. Mater. Sci. Eng. 12 (2004) 1251-1266.

[31] L.P. Biró, Z.E. Horváth, G.I. Márk, Z. Osváth, A.A. Koós, A.M. Benito, W. Maser, P. Lambin, Carbon nanotube Y junctions: Growth and properties, Diam. Relat. Mater. 13 (2004) 241-249.

[32] A. Lijima, T. Ichihashi, Y. Ando, Pentagons, heptagons and negative curvature in graphite microtubule growth, Nature 356 (1992) 776-778.

[33] S. Jalili, M. Akhavan, J. Schofield, Electronic and structural properties of BC3 nanotubes with defects, J. Phys. Chem. C 116 (2012) 13225-13230.

[34] Z. Chen, W. Thiel, A. Hirsch, Reactivity of the convex and concave surfaces of singlewalled carbon nanotubes (SWCNTs) towards addition reactions: Dependence on the carbonatom pyramidalization, ChemPhysChem. 4 (2003) 93-97.

[35] K. Ramachandran, T. Raj Kumar, K.J. Babu, G. Gnana Kumar, Ni-Co bimetal nanowires filled multiwalled carbon nanotubes for the highly sensitive and selective non-enzymatic glucose sensor applications, Sci. Rep. 6 (2016) 1-12. 
[36] A.C. Ferrari, J. Robertson, Interpretation of Raman spectra of disordered and amorphous carbon, Phys. Rev. B 61 (2000) 14095-14107.

[37] N.G. Tsierkezos, P. Szroeder, R. Fuge, U. Ritter, Electrochemical studies on novel films consisting of phosphorus-doped multi-walled carbon nanotubes, Ionics 21 (2015) 1081-1088.

[38] J.C. Myland, K.B. Oldham, Uncompensated resistance. The effect of cell geometry, Anal. Chem. 72 (2000) 3972-3980.

[39] Y.H. Wen, H.M. Zhang, P. Qian, H.T. Zhou, P. Zhao, B.L. Yi, Y.S. Yang, A study of the $\mathrm{Fe}(\mathrm{III}) / \mathrm{Fe}(\mathrm{II})$-triethanolamine complex redox couple for redox flow battery application, Electrochim. Acta 51 (2006) 3769-3775.

[40] R.S. Nicholson, I. Shain, Theory of stationary electrode polarography single scan and cyclic methods applied to reversible, irreversible, and kinetic systems, Anal. Chem. 36 (1964) 706-723.

[41] R.J. Bowling, R.T. Packard, R.L. McCreery, Activation of highly ordered pyrolytic graphite for heterogeneous electron transfer: relationship between electrochemical performance and carbon microstructure, J. Am. Chem. Soc. 111 (1989) 1217-1223.

[42] R.J. Bowling, R.T. Packard, R.L. McCceery, Mechanism of electrochemical activation of carbon electrodes: role of graphite lattice defects, Langmuir 5 (1989) 683-688.

[43] Y.W. Alsmeyer, R.L. McCreery, Surface-enhanced Raman spectroscopy of carbon electrode surfaces following silver electrodeposition. Anal. Chem. 63 (1991) 1289-1295.

[44] H. Peng, G. Ma, J. Mu, K. Sun, Z. Lei, Low-cost and high energy density asymmetric supercapacitors based on polyaniline nanotubes and $\mathrm{MoO}_{3}$ nanobelts, J. Mater. Chem. A 2 (2014) 10384-10388. 
[45] P. Suresh, A.K. Shukla, N. Munichandraiah, Temperature dependence studies of a.c. impedance of lithium-ion cells, J. Appl. Electrochem. 32 (2002) 267-273.

[46] N.G. Tsierkezos, P. Szroeder, U. Ritter, Multi-walled carbon nanotubes as electrode materials for electrochemical studies of organometallic compounds in organic solvent media. Monatsh. Chem. 142 (2011) 233-242.

[47] A. Afkhami, A. Bahiraei, T. Madrakian, Gold nanoparticle/multi-walled carbon nanotube modified glassy carbon electrode as a sensitive voltammetric sensor for the determination of diclofenac sodium, Mater. Sci. Eng. C Mater. Biol. Appl. 59 (2016) 168-176.

[48] Y.Z. Song, Y. Song, H. Zhong, Gold nanoparticle/double-walled carbon nanotubemodified glassy carbon electrode and its application, Gold Bull. 44 (2011) 107-111.

[49] H. Razmi, M. Agazadeh, B. Habibi, Electrocatalytic oxidation of dopamine at aluminum electrode modified with nickel pentacyanonitrosylferrate films, synthesized by electroless procedure, J. Electroanal. Chem. 547 (2003) 25-33.

[50] Z. Jia, J. Liu, Y.B. Shen, Fabrication of a template-synthesized gold nanorod-modified electrode for the detection of dopamine in the presence of ascorbic acid, Electrochem. Commun. 9 (2007) 2739-2743.

[51] C. Deng, J. Chen, M. Yang, Z. Nie, S. Si, Electrochemical determination of dopamine in the presence of ascorbic acid based on the gold nanorods/carbon nanotubes composite film. Electrochim. Acta 56 (2011) 8851-8856.

[52] S.F. Wang, D. Dan, Q.C. Zou, Electrochemical behavior of epinephrine at 1-cysteine selfassembled monolayers modified gold electrode, Talanta 57 (2002) 687-692.

[53] H.M. Zhang, X.L. Zhou, R.T. Hui, N.Q. Li, D.P. Liu, Studies of the electrochemical behavior of epinephrine at a homocysteine self-assembled electrode, Talanta 56 (2002) 10811088. 
[54] M.D. Hawley, S.V. Tatawawadi, S. Piekarski, R.N. Adams, Electrochemical studies of the oxidation pathways of catecholamines, J. Am. Chem. Soc. 89 (1967) 447-450.

[55] J.L. Owens, H.A. Marsh, G. Dryhurst, Electrochemical oxidation of uric acid and xanthine: an investigation by cyclic voltammetry, double potential step chronoamperometry and thinlayer spectroelectrochemistry, J. Electroanal. Chem. 91 (1978) 231-247.

[56] C.M.A. Brett, A.M.O. Brett, Electroanalysis, Oxford University Press Inc, New York, 1998.

[57] J. Mocak, A.M. Bond, S. Mitchell, G. Scollary, A statistical overview of standard (IUPAC and ACS) and new procedures for determining the limits of detection and quantification: Application to voltammetric and stripping techniques, Pure Appl. Chem. 69 (1997) 297-328.

[58] G.A. Long, J.D. Winefordner, Limit of detection. A closer look at the IUPAC definition, Anal. Chem. 55 (1983) 712-724. 